\title{
Nanostructured down-converter module for photovoltaic application
}

\author{
Thierry Deschamps ${ }^{\mathrm{a}, \mathrm{b}}$, Antoine Guille ${ }^{\mathrm{c}}$, Emmanuel Drouard ${ }^{\mathrm{a}, \mathrm{b}}$, Radoslaw Mazurczyk ${ }^{\mathrm{a}, \mathrm{b}}$, Régis \\ Orobtchouk $^{\mathrm{a}, \mathrm{d}}$, Cécile Jamois ${ }^{\mathrm{a}, \mathrm{d}}$, Alain Fave ${ }^{\mathrm{a}, \mathrm{d}}$, Romain Peretti ${ }^{\mathrm{a}, \mathrm{b}}$, Erwann Fourmond ${ }^{\mathrm{a}, \mathrm{d}}$, Antonio \\ Pereira $^{\mathrm{c}}$, Bernard Moine ${ }^{\mathrm{c}}$, Christian Seassal ${ }^{\mathrm{a}, \mathrm{b}, \mathrm{d}}$ \\ ${ }^{a}$ Université de Lyon, Institut des Nanotechnologies de Lyon (INL), UMR 5270, CNRS-INSA-ECL- \\ UCBL, France \\ ${ }^{\mathrm{b}}$ Ecole Centrale de Lyon, 36 Avenue Guy de Collongue, 69134 Ecully Cedex, France \\ 'Institut Lumière Matière, UMR 5306 Université Lyon 1-CNRS, Université de Lyon 69622 \\ Villeurbanne cedex, France \\ ${ }^{\mathrm{d}}$ INSA de Lyon, Bat. Blaise Pascal, 7 Avenue Capelle, 69621 Villeurbanne, France
}

\begin{abstract}
In silicon-based solar cells, a substantial part of the energy losses is related to the charge carriers thermalization in the UV-blue range and the week carriers collection at these wavelenghts. To avoid this issue, we introduce a new concept which combines a rare-earths doped thin layer with a photonic crystal (PC) layer, allowing an efficient conversion from UV-blue photons to near-IR photons. We report on the feasibility of such a nanostructured down-converter module using an active rare-earth doped $\mathrm{CaYAlO}_{4}$ thin layer and a silicon nitride PC on top. By means of optical numerical simulations, the promising potentialities of the concept are demonstrated.
\end{abstract}

Keywords: Spectral converter, down-conversion, quantum-cutting, doped thin layer, nanophotonics, photonic crystals, optical simulations, photovoltaics

\section{INTRODUCTION}

Amongst the various ways of using the renewable solar energy, photovoltaic (PV) systems use has been growing extremely fast in the last decades. Despite these continued efforts, the best yield ever achieved on a crystalline siliconbased solar cell is about $25 \%$. Such performances do not allow the PV energy to reach the grid parity. Therefore, developing and implementing innovative solutions have become a crucial challenge for the research on renewable energies. Several routes are currently explored in order to enhance the PV cells yield while reducing the use of raw materials. These groundbreaking systems, grouped in the so-called "third generation PV cells", include ultra-thin nanostructured silicon layer ${ }^{3-7}$, multi-junction devices ${ }^{8}$, dye-sensitized cells ${ }^{9,10}$, and cells combined with frequency converter layers $^{11}$. This last concept, which could allow to overcome the Shockley-Queisser limit for single junction cells, is extremely promising. Indeed, the c-Si based solar cells, which largely dominate the PV market, present currently some serious limitations due to the mismatch between the solar spectrum and the semiconductor sensibility ${ }^{12}$. In the infrared domain, photons with energy less than the band gap $(\lambda>1150 \mathrm{~nm})$ are not absorbed. In the UV-blue range, a single electron-hole pair is created after photon absorption, but the excess energy is lost by charge-carrier thermalization. Because the thermalization processes by increasing the temperature of the device, reduce the solar cell efficiency and furthermore degrade the solar cells and so reduce their lifetime, the modules are designed in such a way that highest energy photons $(\lambda>400 \mathrm{~nm})$ are absorbed by a low-iron glass placed on the front part of solar panels. Hence, a significant portion of the solar spectrum is today unused (Fig.1). The goal of frequency converters is to modify the solar spectrum and adapt it to the semiconductor spectral response. Two emerging concepts, based on rare-earths doped thin layer, are being considered: the up-conversion ${ }^{13,14}$ and the down-conversion ${ }^{15-19}$ processes. Up-conversion which leads after two or more photons absorption to the emission of light at shorter wavelengths, could allow for the use of photons with energy lower than the band gap. Several rare-earth ions, namely Erbium ${ }^{20}$, show emission suitable for c-Si, but suffer from low absorption. Although this type of converter layer would be located at the back side of the cell, both the low cross-section and the two steps absorption are clearly major draw-backs which seem to limit the interest of such device.

*christian.seassal@ec-lyon.fr; phone +330472186064

Physics, Simulation, and Photonic Engineering of Photovoltaic Devices II, edited by Alexandre Freundlich,

Jean-Francois Guillemoles, Proc. of SPIE Vol. 8620, 86200G · C 2013 SPIE

CCC code: $0277-786 X / 13 / \$ 18 \cdot$ doi: $10.1117 / 12.2003640$

Proc. of SPIE Vol. $862086200 \mathrm{G}-1$ 
Concerning down-conversion by quantum cutting process, meaning the emission of 2 photons after one absorbed, the converter layer has to be placed on the front side of the cell. The role of this device is to absorb UV-blue photons and to convert them, with a multiplication phenomenon, into IR photons near the maximum of sensibility of c-Si. Several couples of rare-earth ions have been studied for such application. Key examples include $\left\{\mathrm{Pr}^{3+} ; \mathrm{Yb}^{3+}\right\},\left\{\mathrm{Tm}^{3+} ; \mathrm{Yb}^{3+}\right\}$ and $\left\{\mathrm{Tb}^{3+} ; \mathrm{Yb}^{3+}\right\}$ where $\mathrm{Yb}^{3+}$ is used as the emitting ion at $980 \mathrm{~nm}^{17-19}$. At this stage, the same limitation as up-conversion occurs, meaning the low absorption cross-section of the $4 \mathrm{f}-4 \mathrm{f}$ inter-configurational transitions.

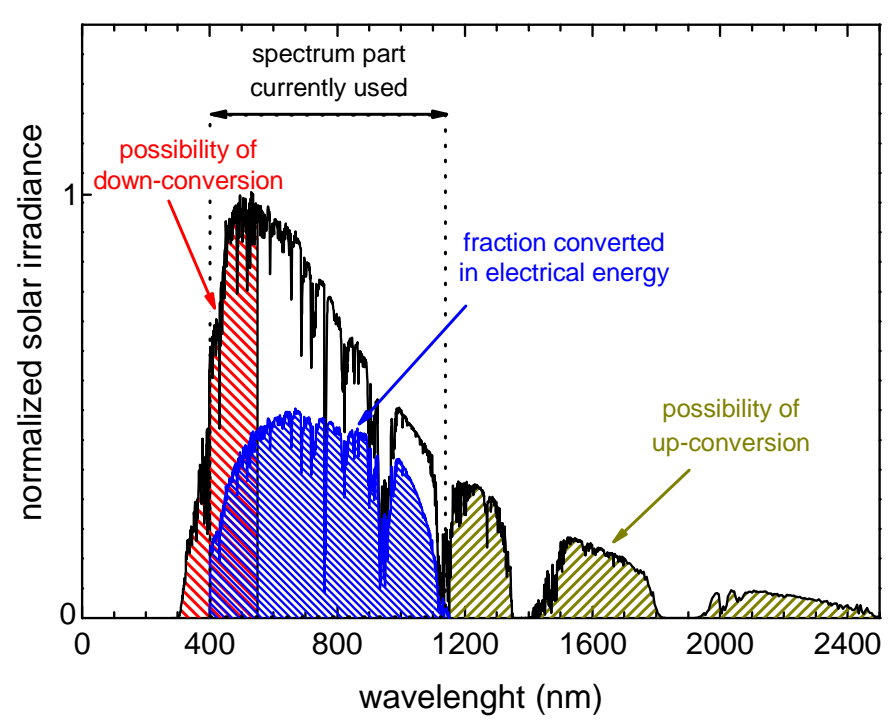

Figure 1: Normalized AM1.5G solar spectrum irradiance. Only the range [400nm-1150nm] is used in current c-Si solar cells. Above 1150nm, photons are not absorbed but can be converted by up-conversion mechanism. Beneath 550nm, the photons frequency can be shifted by down-conversion process.

Two solutions have already been considered to enhance the rare-earth ions absorption: the coupling with nanoparticules plasmon resonances ${ }^{21}$, and the addition of a third rare-earth ion. Indeed, for down-conversion application, a third rareearth ion presenting a 4f-5d parity-allowed transition in UV range can be added to override this issue. The influence of the crystal field in the energy level of this intra-configurational transition restricts the host matrix choice. $\mathrm{Ce}^{3+}$ in $\mathrm{CaYAlO}_{4}$ have already shown good properties, with 4f-5d absorption band between 300 and $400 \mathrm{~nm}^{18}$.

During the last decades, the development of nanotechnology and the emergence of new concepts allowing photons management at the wavelength scale have open new ways for photovoltaic application ${ }^{22}$. In particular, nanophotonic structures like photonic crystals offer efficient strategies in order to increase the absorption in thin layers. This type of structures exhibit original dispersion properties, namely photonic Bloch modes with slow group velocity which enhance the photons lifetime in the PC, and therefore increase its absorption.

In this paper, we present the feasibility of an efficient down-converter module based on a thin $\mathrm{CaYAlO}_{4}$ doped layer coupled to a photonic crystal (PC) in order to enhance the absorption and conversion efficiency. We first describe the proposed concept, then the thin layer depositions and the nanofabrication methodologies. Results of numerical simulations, showing the potentiality of this approach, are presented.

\section{DOWN-CONVERTER MODULE PROPOSED}

\subsection{General concept}

The goal of the innovative down-converter module proposed here is to efficiently convert the UV-blue photons of the solar spectrum into near IR photons around the peak of sensitivity of c-Si. To achieve this, we proposed to associate a 
frequency converter thin layer with a planar photonic crystal allowing the control of light-matter interaction. In particular, thanks to the dispersion properties of such photonic structures, slow light modes can be introduced into the doped layer at frequencies fixed by the geometrical parameters of the PC. The enhancement of the photon lifetimes would therefore allow for an important increase of the rare-earth ions absorption. Several constraints guide the choice of the material constituting the PC. This later must be both highly transparent in the whole solar spectrum range (at least up to the c-Si gap), exhibit a relatively high refractive index, and be compatible with usual etching process. Silicon nitride, which satisfies those requirements, is used in this study. In addition to the absorption enhancement, the photonic crystal will have to be designed with a high angular acceptance and to control the directivity of the near-IR emission, while remaining transparent in the visible and IR domains.

\subsection{Active quantum-cutter thin layer composition}

The active thin layer chosen for down-conversion is a $\mathrm{CaYAlO}_{4}$ ceramic doped with the couple $\left\{\mathrm{Pr}^{3+} ; \mathrm{Yb}^{3+}\right\}$ enabling the

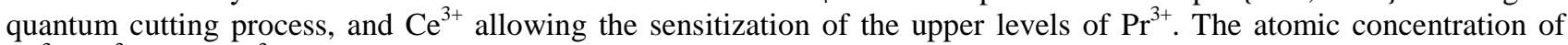
$\mathrm{Ce}^{3+}, \mathrm{Pr}^{3+}$, and $\mathrm{Yb}^{3+}$ are respectively $0.5 \%, 1.5 \%$ and $10 \%$. In such a doped matrix, the incident UV-blue photons between $320 \mathrm{~nm}$ and $380 \mathrm{~nm}$ can be absorbed due to the broad absorption of $\mathrm{Ce}^{3+}$. Because the emission band of $\mathrm{Ce}^{3+}$ overlaps the excitations band of the ${ }^{3} \mathrm{P}_{\mathrm{j}}$ levels of $\mathrm{Pr}^{3+}$, these last levels can be excited by energy transfers between $\mathrm{Ce}^{3+}$ and $\mathrm{Pr}^{3+}$. Finally, the quantum-cutting process occurs by a two steps energy transfer mechanisms from $\mathrm{Pr}^{3+}$ to $\mathrm{Yb}^{3+}$. The various stages leading to the $\mathrm{Yb}^{3+}$ emission are schematized figure 2. More explanations can be found in Ref [18].

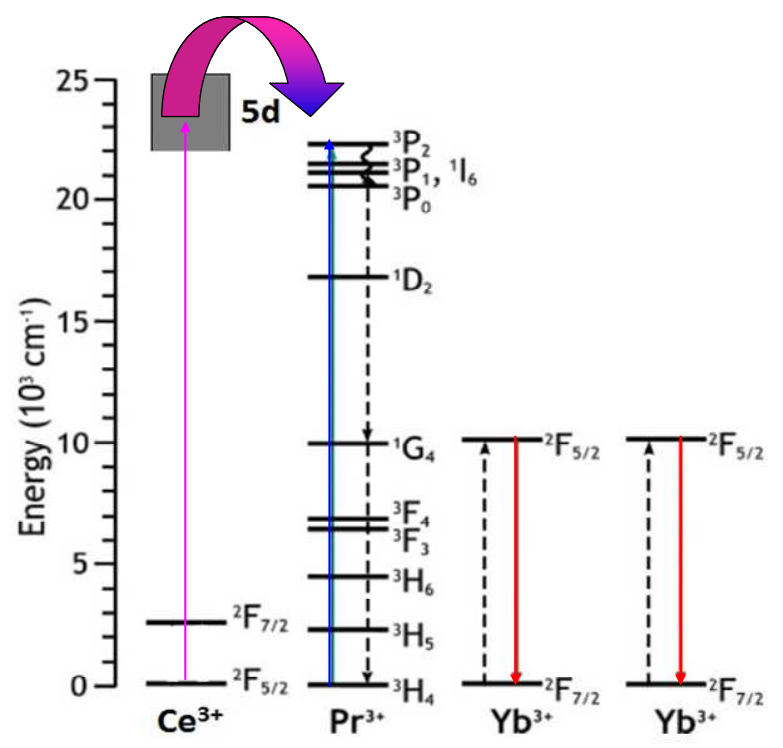

Figure 2. Energy transfers between rare-earth ions in $\mathrm{CaYAlO}_{4}$ codoped with $\mathrm{Ce}^{3+}, \mathrm{Pr}^{3+}$ and $\mathrm{Yb}^{3+}$. The presence of the $4 \mathrm{f}-5 \mathrm{~d}$ transition allow an efficient absorption between 320 and $380 \mathrm{~nm}$. The ${ }^{3} \mathrm{P}_{\mathrm{j}}$ levels are than excited by energy transfer from Ce ${ }^{3+}$ to $\mathrm{Pr}^{3+}$. The two steps de-excitation of $\operatorname{Pr}^{3+}$ conducted by energy transfers between $\mathrm{Pr}^{3+}$ and $\mathrm{Yb}^{3+}$ leads to the emission of 2 IR photons, a process called quantum-cutting.

\section{MODULE ELABORATION}

\subsection{Active rare-earth doped and $\mathrm{Si}_{3} \mathrm{~N}_{4}$ thin layers deposition}

In order to synthesize the doped $\mathrm{CaYAlO}_{4}$ thin film, a conventional pulsed laser deposition (PLD) method was used. This technique involved the use of a high power UV laser beam focused on a target of the desired composition. Material is then ejected from the target and deposited on a substrate facing the target. In these experiments, the pulsed laser used for the deposition was an ArF excimer laser (Coherent CompexPRO 201F) operating at $\lambda=193 \mathrm{~nm}$ and having a pulse duration of $\tau=25 \mathrm{~ns}$. The laser beam was focused on the surface of a $\mathrm{Ce}^{3+}, \mathrm{Pr}^{3+}$ and $\mathrm{Yb}^{3+}$ tri-doped $\mathrm{CaYAlO}_{4}$ target located inside a vacuum chamber (base pressure of $1.10^{-7} \mathrm{mbar}$ ) at an angle of $45^{\circ}$. The deposition were performed in an oxygen gas atmosphere $\left(\mathrm{P}_{\mathrm{O} 2}=10^{-2} \mathrm{mbar}\right)$ in order to ensure the $\mathrm{CaYAlO}_{4}$ stoichiometry with a laser fluence kept constant 
at $2{\mathrm{~J} . \mathrm{cm}^{-2}}^{-2}$. The films were deposited on $\mathrm{SiO}_{2}$ substrates held at room temperature and fixed $4 \mathrm{~cm}$ from the target. Films thickness and deposition rate were first determined by the m-lines technique. The number of laser pulses was then adjusted to achieve films of $100 \mathrm{~nm}$ thick.

The $\mathrm{Si}_{3} \mathrm{~N}_{4}$ layer was deposited on the top of $\mathrm{CaYAlO}_{4}$ by low-frequency plasma-enhanced chemical vapor deposition (LF-PECVD) direct method, using a $440 \mathrm{kHz}$ SEMCO-Engineering reactor ${ }^{23}$. The $\mathrm{SiN}_{\mathrm{x}}$ stoichiometry was controlled, adjusting the ammonia-to-silane gas flow ratio $\mathrm{NH}_{3} / \mathrm{SiH}_{4}$. The temperature at $\mathrm{T}=370^{\circ} \mathrm{C}$ and all the other physical parameters (pressure, plasma power and total gas flow) were maintained constant. The deposition rate was also measured to control the thickness.

\section{2 $\mathrm{Si}_{3} \mathrm{~N}_{4}$ structuration}

In order to pattern the silicon nitride layer as a 2D PC membrane while meeting industrial requirements, it is essential to use a process compatible with large surfaces. Holographic lithography is well suitable for such applications. This technique consists of irradiating a photosensitive resist, previously deposited on the material to structure, using an interference pattern. A simple way to achieve this is to place the coated sample on a sample holder associated to a mirror at $90^{\circ}$. A $2 \mathrm{D}$ pattern with square symmetry can be then obtained by a second exposure after tilting the sample by $90^{\circ}$. After holographic lithography and resist development, reactive ion etching could be used to transfer the resist pattern to the silicon nitride layer. More details concerning $\mathrm{Si}_{3} \mathrm{~N}_{4}$ patterning is presented section 5 .

\section{OPTICAL SIMULATIONS RESULTS}

In this section is presented the results of optical simulations by means of Finite-Differential Time-Domain (FDTD) approach. The source used is a normal incident plane wave in the range $250-1200 \mathrm{~nm}$, which delimit respectively the UV limit of the solar spectrum and the band gap of $\mathrm{c}-\mathrm{Si}$. The photonic crystal has been designed in order to enhance the absorption of $\mathrm{Ce}^{3+}$ ions between 300 and $400 \mathrm{~nm}$ while retaining a good transmission in the whole spectral range.

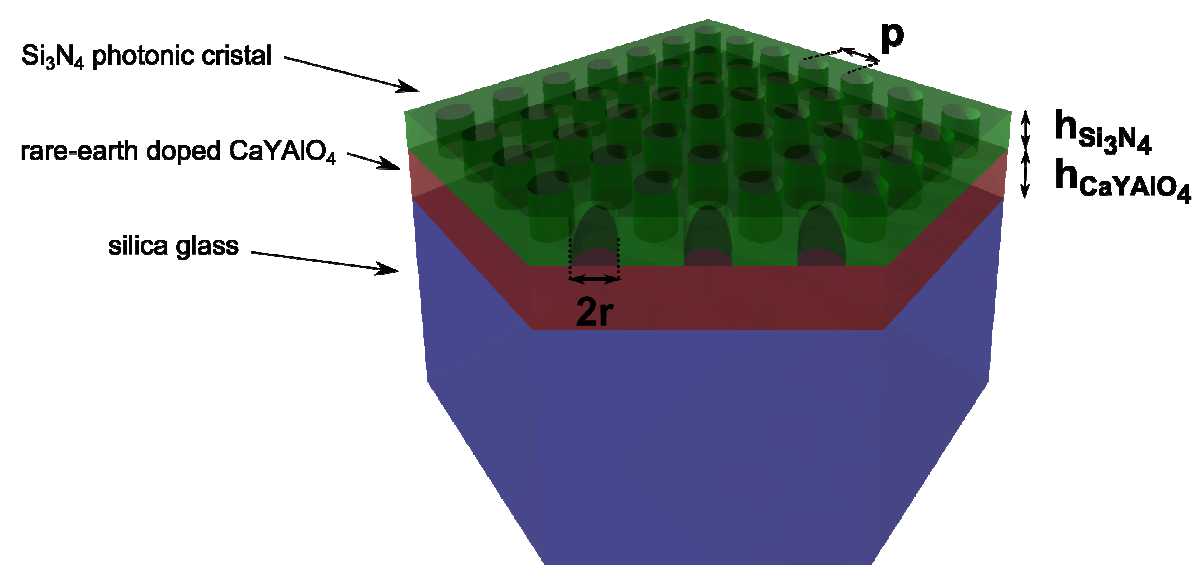

Figure 3. Stack and parameters of the nanostructured photonic crystal used for the numerical simulation.

The doped ceramic thickness has been fixed at 100nm. This layer stands on silica glass which thickness is supposed to be semi-infinite thanks to the use of perfectly matched layers. Above the doped layer is a thin film of silicon nitride nanostructured as a 2D PC. This periodic square lattice of holes is computed using Bloch-periodic boundary conditions. Concerning the implemented optical properties (n,k parameters) of these materials, the $\mathrm{SiO}_{2}$ and $\mathrm{Si}_{3} \mathrm{~N}_{4}$ dispersion curves from Palik data ${ }^{24}$ have been used. For the ceramic material, we have measured by spectroscopic ellipsometry the dispersion curve of a non-doped $\mathrm{CaYAlO}_{4}$ thin film, and fitted it with the Lorentz model. At last, the Ce ${ }^{3+}$ absorption 
cross-section has been calculated from the luminescence lifetime of the $5 \mathrm{~d}$ level using the Einstein coefficients relation. Series of numerical simulations have been performed in order to optimize the PC parameters, relying in particular on previous theoretical works of our group involving light trapping in $\mathrm{PC}^{25,26}$. The $\mathrm{PC}$ parameters finally obtained are displayed figure 3 . All the simulation results exposed further arise from this geometry.

\subsection{UV resonant modes in the photonic cristal}

Figure 4 shows the resonant modes in the UV range in the nanostructured layer excited by an in-plane polarized short femtosecond pulselength dipole around $350 \mathrm{~nm}$. The quality factors of these two modes, peaked at $347 \mathrm{~nm}$ and $356 \mathrm{~nm}$, are respectively of 80 and 70. Although weakly resonant, they match well with the large absorption band of $\mathrm{Ce}^{3+}$ present in the underneath layer.

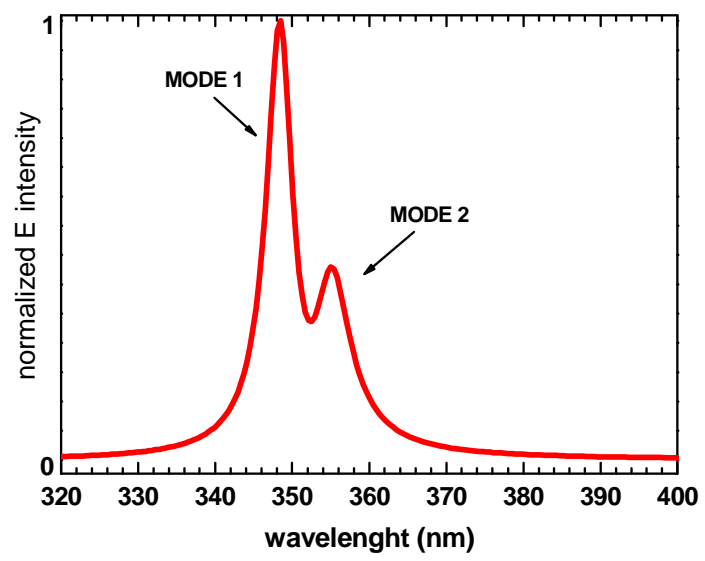

Figure 4: resonant modes in the PC structure in the UV range. The mode $1\left(\mathrm{Q}_{1}=80\right)$ and the mode $2\left(\mathrm{Q}_{2}=70\right)$ are respectively peaked at $347 \mathrm{~nm}$ and $356 \mathrm{~nm}$.

\section{MODE 1}

(a)

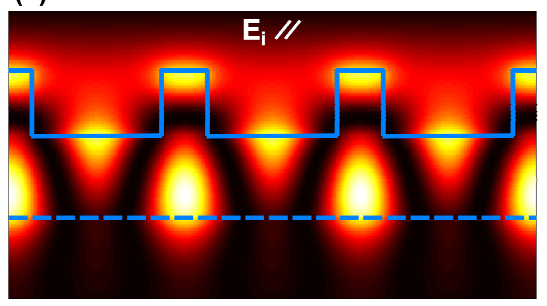

(b)

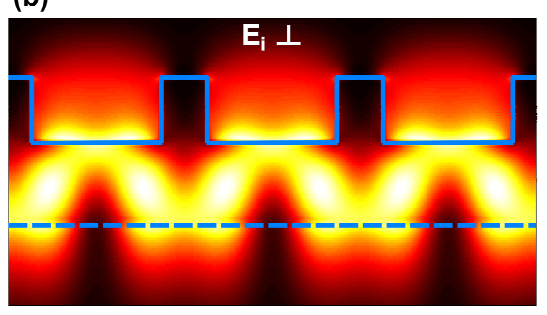

MODE 2

(c)

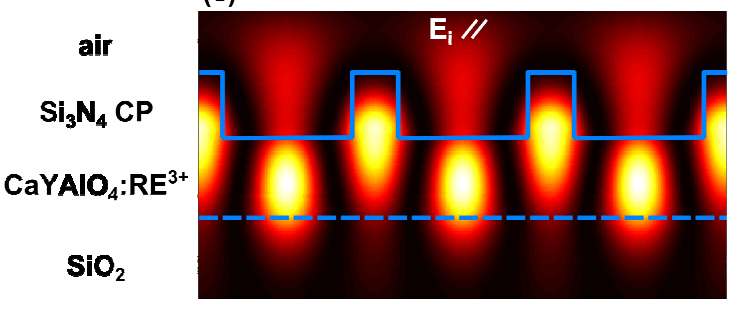

(d)

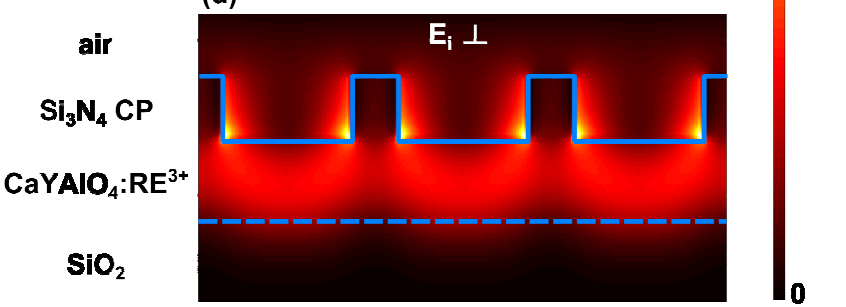

Figure 5. Mapping of the electric field intensity of the mode 1 (at $347 \mathrm{~nm}$ ) and the mode 2 (at $356 \mathrm{~nm}$ ) in the different layers of the stack obtained by numerical simulations. (a) and (c) represent respectively the cartography of the mode 1 and the mode 2 in the plane parallel to the incident electric field. (b) and (d) display respectively the cartography of the mode 1 and the mode 2 in the plane orthogonal to the incident electric field. The two UV modes are largely located in the rare-earth doped ceramic layer, showing the relevance of such patterning. 
Different maps of the electric field intensity, function of the incident polarizations, are displayed figure 5. The source used for these simulations is a normal incident plane wave linearly polarized, and the maps show the field intensity of the two resonant modes in the parallel and orthogonal planes with respect to the incident electric field polarization. One can observe that the two modes are mainly located in the rare-earth doped layer. The UV light can therefore efficiently be absorbed by the $\mathrm{Ce}^{3+}$ ions.

\subsection{Absorption and transmission of the down-converter module}

In order to quantify the enhancement of the $\mathrm{Ce}^{3+}$ ions absorption by the $\mathrm{Si}_{3} \mathrm{~N}_{4}$ patterning, we have simulated the transmission spectra of a normal incident UV plane-wave source respectively at the $\mathrm{Si}_{3} \mathrm{~N}_{4} / \mathrm{CYA}$ and $\mathrm{CYA} / \mathrm{SiO}_{2}$ interfaces. The $\mathrm{Ce}^{3+}$ absorption deduced from this simulation is displayed figure 6a, within the calculated Beer-Lambert absorption of the same $\mathrm{CaYAlO}_{4}$ layer. A large effect of the PC on the enhancement of the absorption is observed. Namely, the integrated absorption between 320 and 400nm is increased by a factor 10 .

(a)

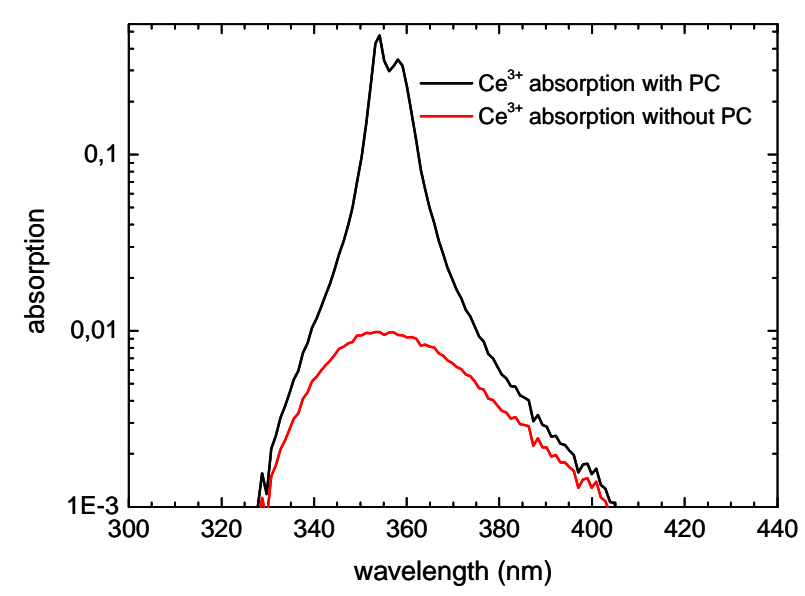

(b)

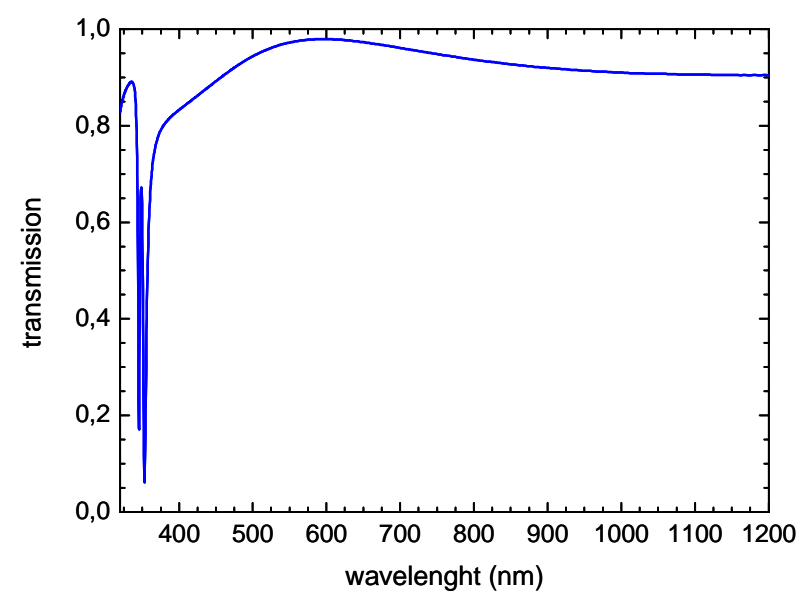

Figure 6: (a) simulated absorption of the $\mathrm{Ce}^{3+}$ ions in the $\mathrm{CaYAlO}_{4}$ layer with and without $\mathrm{Si}_{3} \mathrm{~N}_{4} \mathrm{PC}$. (b) Simulated transmission of the down-converter module in the range 320-1200nm.

Figure $6 \mathrm{~b}$ shows the transmission of the whole stack in the $[320 \mathrm{~nm}-1150 \mathrm{~nm}]$ wavelengths range. In the UV range, the light which is not absorbed by the doped ceramic is reflected. In the visible and near IR ranges, the module displays a very good transmission: between $80 \%$ and $90 \%$ in the $400-450 \mathrm{~nm}$ interval, and between $90 \%$ and $98 \%$ above $450 \mathrm{~nm}$.

Thus, the results of the optical simulations are extremely promising with the aim of developing an efficient downconverter module combined rare-earth doped thin layer and photonic crystal. Already two fundamental criteria are fulfilled: the efficient absorption below $400 \mathrm{~nm}$, and the good transmission above this wavelength. Optimizations are in progress to control the directivity of the $980 \mathrm{~nm}$ emission.

\section{PHOTONIC CRYSTAL FABRICATION}

We implemented the holographic lithography process described section 3.2 using a $266 \mathrm{~nm}$ laser source with a $10 \mathrm{~mW}$ power, and a NEB 22 negative tone chemically amplified resist in order to generate a pattern of holes in the structure. To show the feasibility of such patterning, the silicon nitride layer, of $150 \mathrm{~nm}$ thickness, has been deposited on a crystalline silicon substrate. After a 120 s post exposure bake at $92^{\circ}$, the resist has been developed using a MF702 solution. A final etch step by Reactive Ion etching (RIE) have been performed to transfer the resist pattern to the $\mathrm{Si}_{3} \mathrm{~N}_{4}$ layer. This transfer has been achieved using a mixture of $\mathrm{CH}_{4}, \mathrm{CHF}_{3}$ and $\mathrm{SF}_{6}(2 \mathrm{sccm}, 45 \mathrm{sccm}$ and $25 \mathrm{sccm}$ respectively) plasma with a 
pressure of $100 \mathrm{mTorr}$ and a power of 100W. $2 \mathrm{SEM}$ images of a patterned $\mathrm{Si}_{3} \mathrm{~N}_{4}$ thin layer on $\mathrm{Si}$ substrate are displayed Figure 7.

(a)

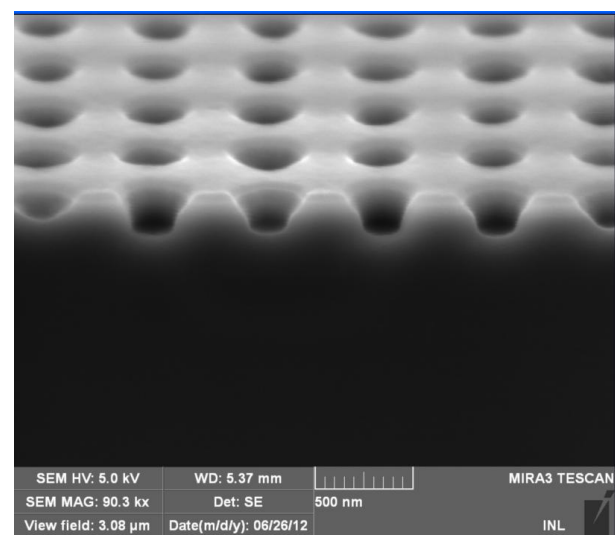

(b)

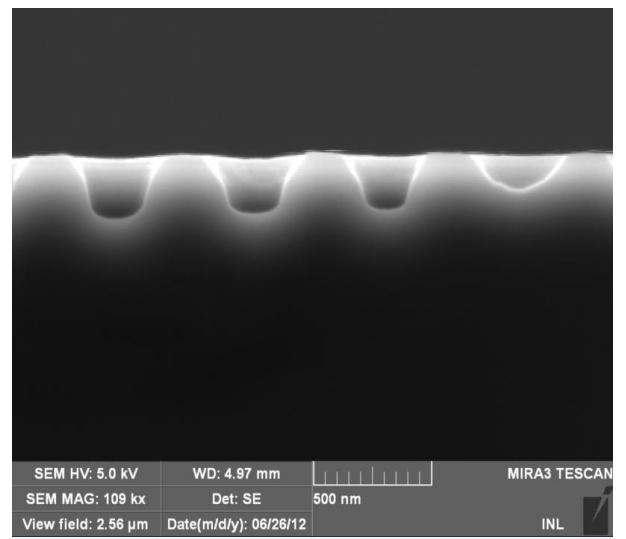

Figure 7. SEM profile images of etched silicon nitride thin layer (150nm thickness) after holographic lithography experiments. (a) The SEM image of the surface showed the square symmetry of the holes pattern. (b) Etch sides of the $\mathrm{Si}_{3} \mathrm{~N}_{4}$ layer.

These images clearly show the feasibility of the $\mathrm{Si}_{3} \mathrm{~N}_{4}$ structuration as a photonic crystal. Works are now in progress in order to realise the $\mathrm{Si}_{3} \mathrm{~N}_{4}$ patterning on the $\mathrm{SiO}_{2} / \mathrm{CaYAlO}_{4}: \mathrm{RE}^{3+}$ stack, and to characterize optically such structures.

\section{CONCLUSION}

To conclude, we have introduced a new concept combining rare-earth doped thin layers and photonic crystals in order to enhance the efficiency of down-conversion with quantum cutting process for photovoltaic applications. Results of optical numerical simulations have revealed the potentiality of this approach: the absorption of the $\mathrm{Ce}^{3+}$ ions in the UV range can be increased by a factor 10 without disturbing the visible and near-IR parts of the spectrum. The different fabrication steps to elaborate the complete down-converter module have been realised. We also demonstrated the feasibility of the silicon nitride photonic crystal, allowing the introduction of UV resonant modes in the nanostructure. Works are in progress to optimize the whole transmission and the directivity of the $\mathrm{Yb}^{3+}$ emission, and to characterize experimentally the converter module.

The authors are grateful to the Program "Investissements d'Avenir"- launched by the French Government and operated by the National Research Agency (ANR) - for financial support to the LabEx iMUST of Universite de Lyon. The technology platform NanoLyon is also gratefully acknowledged for its technical support.

\section{REFERENCES}

[1] Davis, A. Zhao, J., Wang, A. and Green, M. A., "24.5\% Efficiency Silicon PERT Cells on MCZ Substrates and 24.7\% Efficiency PERL Cells on FZ Substrates,” Prog. Photovolt: Res. Appl. 7, 471-474 (1999).

[2] Green, M. A., Emery, K., Hishikawa, Y., Warta, W., and Dunlop, E. D., "Solar cell efficiency tables (version 39)," Prog. Photovolt: Res. Appl. 20, 12-20 (2012).

[3] Park, Y., Drouard, E., El Daif, O., Letartre, X., Viktorovitch, P., Fave, A., Kaminski, A., Lemiti, M. and Seassal., C., "Absorption enhancement using photonic crystals for silicon thin film solar cells," Opt. Express 17(16),14312-14321 (2009). 
[4] El Daif, O., Drouard, E., Gomard, G., Kaminski, A., Fave, A., Lemiti, M., Ahn, S., Kim, S., Roca i Cabarrocas, P., Jeon, H. and Seassal, C., "Absorbing one-dimensional planar photonic crystal for amorphous silicon solar cell,” Opt. Express, 18(S3), A293-A299 (2010).

[5] Gomard, G., Drouard, E., Letartre, X., Meng, X., Kaminski, A., Fave, A., Lemiti, M., Garcia-Caurel, E. and Seassal, C., "Two-dimensional photonic crystal for absorption enhancement in hydrogenated amorphous silicon thin film solar cells," J. Appl. Phys. 108(12), 123102 (2010).

[6] Meng, X., Gomard, G., El Daif, O., Drouard, E., Orobtchouk, R., Kaminski, A., Fave, A., Lemiti, M., Abramov, A., Roca i Cabarrocas, P. and Seassal, C., "Absorbing photonic crystals for silicon thin-film solar cells: Design, fabrication and experimental investigation," Sol. Energy Mater. Sol. Cells 95, S32-S38 (2011).

[7] Gomard, G., Meng, X., Drouard, E., El Hajjam, K., Gerelli, E., Peretti, R., Fave, A., Orobtchouk, R., Lemiti, M. and Seassal, C., "Light harvesting by planar photonic crystals in solar cells: the case of amorphous silicon," J. Opt. 14(2), 024011 (2012).

[8] Yamaguchi, M., Takamoto, T., Khan, A., Imaizumi, M., Matsuda, S. and Ekins-Daukes, N. J., "Super-highefficiency multi-junction solar cells," Prog. Photovolt: Res. Appl. 13, 125-132 (2005).

[9] O’Regan, B. and Gratzel, M., "A low-cost, high-efficiency solar cell based on dye-sensitized colloidal TiO2 films," Nature 353(6346), 737-740 (1991).

[10]Chiba, Y., Islam, A., Watanabe, Y., Komiya, R., Koide, N. and Han, L. "Dye-Sensitized Solar Cells with Conversion Efficiency of 11.1\%," Jpn. J. Appl. Phys. 45(25), L638-L640 (2006).

[11]Huang, X., Han, S., Huang, W. and Liu, X., "Enhancing solar cell efficiency: the search for luminescent materials as spectral converters," Chem. Soc. Rev. 42, 173-201 (2013).

[12] Strümpel, C., McCann, M., Beaucarne, G., Arkhipov, V., Slaoui, A., Svrcek, V., del Canizo, C. and Tobias, I., "Modifying the solar spectrum to enhance silicon solar cell efficiency: an overview of avalaible materials," Sol. Energy Mater. Sol. Cells 91, 238-249 (2007).

[13] Su, L. T., Karuturi, S. K., Luo, J., Liu, L., Liu, X., Guo, J., Sum, T. C., Deng, R., Fan, H. J., Liu, X. and Tok, A. I. Y., "Photon upconversion in hetero-nanostructured photoanodes for enhanced near-infrared light harvesting," Adv. Mater. DOI: 10.1002/adma.201204353 (2013).

[14] Xie, X. and Liu, X., "Photonics: upconversion goes broadband," Nature Materials 11, 842-843 (2012).

[15] Van der Ende, B. M., Aarts, L. and Meijerink, A., "Near-infrared quantum cutting for photovoltaics," Adv. Mater. 21(30), 3073-3077 (2009).

[16] Trupke, T., Green, M. A. and Würfel, P., "Improving solar cell efficiencies by down-conversion of high-energy photons," J. Appl. Phys. 92(3), 1668 (2002).

[17] Guille, A., Pereira, A., Martinet, C. and Moine, B., "Quantum cutting in $\mathrm{CaYAlO}_{4}$ : $\mathrm{Pr}^{3+}, \mathrm{Yb}^{3+}$," Opt. Lett. 37(12), 2280-2282 (2012).

[18] Guille, A., Pereira, A., Bensalah-Ledoux, A., Breton, G. and Moine, B., "Energy transfer in $\mathrm{CaYAlO}_{4}$ : $\mathrm{Ce}^{3+}$, $\mathrm{Pr}^{3+}$ for sensitization of quantum-cutting with $\mathrm{Yb}^{3+}-\mathrm{Pr}^{3+}$ couple," J. Appl. Phys. 111(4), 043104 (2012).

[19]Zhang, Q. Y., Yang, G. F. and Jiang, Z. H., "Cooperative downconversion in $\mathrm{GdAl}_{3}\left(\mathrm{BO}_{3}\right)_{4}: \mathrm{RE}^{3+}, \mathrm{Yb} \mathrm{b}^{3+}(\mathrm{RE}=\mathrm{Pr}$, Tb, and Tm)," Appl. Phys. Lett. 91(5), 051903 (2007).

[20] Shalav, A., Richard, B. S., Trupke, T., Krämer, K. W. and Güdel, H. U., "Application of NaYF $4: \mathrm{Er}^{3+}$ upconverting phosphors for enhanced near-infrared silicon solar cell response,” Appl. Phys. Lett. 86(1), 013505 (2005).

[21]Pillonnet, A., Berthelot, A., Pereira, A., Benamara, O., Derom, S., Colas des Francs, G. and Jurdyc, A.M., "Coupling distance between Eu ${ }^{3+}$ emitters and Ag nanoparticules," Appl. Phys. Lett. 100(15), 153115 (2012).

[22] John, S., "Why trap light," Nature Materials 11, 997-999 (2012).

[23] Lelievre, J. F., Fourmond, E., Kaminski, A., Palais, O., Ballutaud, D. and Lemiti, M., "Study of the composition of hydrogenated silicon nitride $\mathrm{SiN}_{\mathrm{x}}: \mathrm{H}$ for efficient surface and bulk passivation of silicon," Sol. Energy Mater. Sol. Cells 93, 1281-1289 (2009).

[24] Palik, E. D., "Handbook of optical constants of solids," CA, San Diego, 771-774 (1998).

[25] Peretti, R., Gomard, G., Seassal, C., Letartre, X. and Drouard, E., "Modal approach for tailoring the absorption in a photonic crystal membrane," J. Appl. Phys. 111(12), 123114 (2012).

[26] Peretti, R., Gomard, G., Seassal, C., Letartre, X. and Drouard, E., "Tailoring the absorption in a photonic crystal membrane: A modal approach," Proc. SPIE 8425, 84250Q-84250Q-9 (2012). 